\title{
Textbook Evaluation: A Reflection on Total English (Intermediate)
}

\author{
Ismail Moazam \\ Department of English Language and Literature, Faculty of Literature and Humanities, Bu-Ali Sina University, Iran
}

Hojat Jodai

Young Researchers Club, Varamin-Pishva Branch, Islamic Azad University, Varamin, Iran

\begin{abstract}
Textbook evaluation plays a very important role in any language teaching or learning program. The present study set out to evaluate "Total English" for intermediate level students based on a checklist adopted from Litz (2005). The researchers weighed the textbook against thirty-five criterial features in the checklist. Furthermore, for the purpose of data triangulation, a five-point-Likert-scale questionnaire including thirty five items was administered to 20 Iranian male and female EFL teachers of varying teaching experiences and university degrees. The checklist included items for external, as well as internal evaluation, then; descriptive statistics was used to interpret the data. The results of the researchers' scrutiny, as well as the descriptive statistics of the questionnaire, indicated that the textbook enjoys good advantages such as a reasonable price, clear layout and effective organization. The results of the study are discussed in details.
\end{abstract}

Index Terms - materials evaluation, evaluation criteria, Total English (Intermediate)

\section{INTRODUCTION}

Tomlinson (2011) defines materials as anything which is used by the teachers or learners to help facilitate the learning of a language whereas materials development refers to anything that is done by writers, teachers and learners to provide sources of language input and exploit those sources in ways that maximize the likelihood of intake. Materials can include "textbooks, cassettes, videos, CD-Rom, dictionaries, grammar books, readers, workbooks, or photocopied exercises"(Tomlinson, 2011, p.2). The term 'textbook' is defined by Merriam Webster (2003) as "a book used in the study of a subject as one containing a presentation of the principles of a subject or as a literary work relevant to the study of a subject." This term, also called text, which is the most prevalent term to refer to a book exploited in teachinglearning situation.

English language teaching has many important components, but the essential constituent to many EFL classrooms and programs is the textbook. Hutchinson and Torres (1994, p. 315) maintain "no teaching-learning situation, it seems, is complete until it has its relevant textbook." Sheldon (1988, p.237) claims that textbooks "represent the visible heart of any ELT program." The view held by the scholars in the field stresses the importance of judicious selection and evaluation of textbooks. Sheldon (1988, cited in Jahangard, 2008) discusses several reasons for material's evaluation. She holds that the selection of an ELT textbook often signals an important administrative and educational decision in which there is considerable professional, financial or even political investment. Williams (1983) maintains, "Any textbook should be used judiciously, since it cannot cater equally to the requirements of every classroom setting" (p. 251). Cunningsworth (1995) discusses the reasons for materials evaluation as follows:

Reasons for material evaluation activities are many and varied. The intention to adopt new course books is a major and frequent reason for evaluation. Another reason is to identify particular strengths and weaknesses in course books already in use, so that optimum use can be made of their strong points, whilst their weaker areas can be strengthened through adaptation or by substituting material from other books (p. 14).

As Total English is one of the most widely used ELT textbooks in Iran context, the present study aimed at evaluating the textbook to shed more light on its adequacy for ELT programs for Iranian, language teachers, and students.

\section{REVIEW OF THE RELATED LITERATURE}

"The wealth of published materials for English language teaching (ELT) available on the market makes selecting the right coursebook a challenging task" (Cunningsworth, 1995, p.1). This statement from Cunningsworth clearly demonstrates the status and significance of the coursebook evaluation in any ELT program. Tomlinson (2003, p.15) defines coursebook evaluation as " a procedure that involves measuring the value (or potential value) of a set of learning materials."

Regarding different forms of materials evaluation, Ellis (1998. et al) distinguishes between macro-evaluation from micro-evaluation: Marco-evaluation can be defined as evaluation that seeks to answer one or both of the following questions: 
1. To what extent was the program/project effective and efficient in meeting its goals?

2. In what way can the program/project be improved?

From another perspective, McGrath (2002) argues for a cyclical approach to material's evaluation that encompasses three stages: pre-use, in-use, and post-use evaluation.

Furthermore, material's evaluation has got different methods (impressionistic and checklist). The impressionistic method is used to obtain a subjective evaluation of the textbook. Cunningsworth (1995) points out that the impressionistic evaluation includes looking at the blurb, table of content, layout, physical format and audio-visuals. This evaluation seems to be inadequate if it is administered solely.

In the checklist method, the researcher weighs the materials against items of the checklist. The most prevalently used checklists are Tucker (1975); Cunningsworth (1984); Breen and Candlin (1987); Sheldon (1988); Hutchinso (1987); McDonough and Shaw (1993); Littlejohn (1998) and Tomlinson (1998).

McGrath (2002, p.27) elaborates on the advantages of checklist method compared to other methods as following:

The present study made an attempt to evaluate Total English using both impressionistic and checklist methods. The results are also triangulated with a teachers' questionnaire responding on the items drawn from the evaluation checklist.

\section{Methodology}

\section{A. Participants}

1. It is systematic, ensuring that all elements that are deemed to be important are considered.

2. It is cost effective, permitting a good deal of information to be recorded in a relatively short space of time.

3. The information is recorded in a convenient format, allowing for easy comparison between competing sets of material.

4. It is explicit, and, provided the categories are well understood by all involved in the evaluation, offers a common framework for decision-making.

Based on the convenience sampling method, 20 EFL teachers teaching Total English Series were chosen by the researchers. The participants were both male and female teachers holding different university degrees, with different teaching experiences.

\section{B. Materials}

Total English ( Clare and Wilson, 2006) Published by Longman publication was taken to serve as the corpus of the present study. The textbook has been designed for young adults and adults and is based on Common European Framework (CEF). It also includes a DVD of audio files and a film bank that can be used to incorporate an authentic film-based lesson into each unit. It was then scrutinized against thirty-five criterial features, the results of which are dealt with in the results section. The seventy-five criterial features are summarized in appendix A.

\section{Data Collection Instrumentation}

In order to evaluate the textbook the researchers scrutinized the textbook based on a checklist adopted from Litz (2005). The evaluation checklist has some criteria pertaining to the physical, organizational, logistical as well as methodological characteristics. Furthermore, some items have been dedicated to the skills and components of the language and topics. Cultural and gender components have also been considered. Finally, some items evaluate the correspondence of the textbook to students' needs and interests.

The following criteria were used to evaluate the textbook:

Furthermore, for the purpose of data triangulation, a five -point structured questionnaire with thirty five items on Likert scale was administered to $10 \mathrm{EFL}$ teachers. To ensure the validity of the researchers' evaluation, a questionnaire was also adopted form Litz (2005).

\section{PROCEDURES}

First, the researchers attempted to choose a systematic and comprehensive evaluation checklist (Litz, 2005). Next, the researchers scrutinized the textbook against criterial features of the evaluation checklist and reported their subjective opinions. Furthermore, to maximize the validity of the researchers' subjective evaluation, a thirty five item questionnaire on Likert scale was administered to 10 EFL teachers teaching the textbook. Descriptive statistics was used to analyze the items of the questionnaire. Finally, the results of the researchers' subjective evaluation as well as those obtained from the questionnaire were compared and contrasted with each other.

\section{RESULTS AND DISCUSSION}

In this section, the researchers' scrutiny of the Total English Intermediate is presented in details.

1. Is the price of the textbook reasonable?

While some believe that the cost is not an important factor in the selection of a textbook, the researchers believe that in countries with less than desirable economic conditions this factor must be an important one to be taken into consideration. Total English Intermediate students is one of the most affordable ELT textbooks compared with other 
current ELT textbooks available on the market. The textbook package including students' edition, workbook and audio CD costs almost 60,000 Rials (about \$20).

2. The textbook is easily accessible?

The textbook is widely published by Logman publication for several times in great circulation, in all over the world. It is still in print and locally well-distributed in Iran.

3. Is the textbook a recent publication?

As far as the textbook was published in 2006 by Longman publication, it seems not to be a recent publication. However, the teachers' idea regarding this item is in contrast with the researchers' subjective evaluation.

4. Is the textbook accompanied by a teacher's guide, workbook, and audio-tapes or CDs?

Rudby (2005) asserts that materials today mostly offer packages for both learners and teachers including workbooks, teachers' guides, audio and video aids and even CALL programs. This is the case for Total English Intermediate which is supported with audio cassettes/ CDs, workbook, teacher's book, photocopiable activities, DVD worksheet activities, Tests, DVD/Video and companion website.

\section{Are the author's views on language and methodology comparable to those held by the evaluators?}

On the blurb, the writers of the textbook claim that the textbook is flexible, clearly structured and is accordance with "Can do" objectives. The textbook is correlated to Common European Framework (CEF) which was developed by the Council of Europe to internationally standardize learning, teaching and assessment of all European languages. The common European Framework (CEF) "provides a common basis for the elaboration of language syllabuses, curriculum guidelines, examinations, textbooks, etc" (CEF, 2001, p.1).

This framework deems a global scale on what the learner can do at six levels from A1, A2, B1, B2, C1, to C2. "Can do" statements for Total English Intermediate include the statements ranging from B1 to B2 which are as follows:

1. Can understand the main points of clear standard input on familiar matters regularly encountered in work, school, leisure, etc.

2. Can deal with most situations likely to arise while traveling in an area where the language is spoken.

3. Can produce simple connected text on topics which are familiar or of personal interest.

4.Can describe experiences and events, dreams, hopes and ambitions and briefly give reasons and explanations for opinions and plans.

5.Can understand the main ideas of complex text on both concrete and abstract topics, including technical discussions in his/her field of specialization.

6. Can interact with a degree of fluency and spontaneity that makes regular interaction with native speakers quite possible without strain for either party.

7. Can produce clear, detailed text on a wide range of subjects and explain a viewpoint on a topical issue giving the advantages and disadvantages of various options.

6. Does the textbook include a detailed overview of the functions, structures and vocabulary that will be taught in each unit?

As mentioned in the previous item, the textbook is based on "Can do" objectives of the Common European framework. This book covers a wide range of functions and topics which are originally based on "can do" objectives. However, regarding the grammatical structures and vocabulary items, the textbook does not provide an overview of what is going to be presented.

7. Are the layout and design appropriate and clear?

As claimed in the blurb, the book has flexible, clearly structured units that make the tough task of teaching and learning easier. The overall design of the books seems to be clear. The textbook includes a user friendly table of contents, 10 units with different sections, grammar reference for each unit, review and practice section at the end of each unit, communication activities at the end of the book, film bank, writing bank, irregular verbs table, pronunciation bank and transcripts.

\section{Is the textbook organized effectively?}

Total English is rather a new textbook in ELT available on the market, the organization of which is relatively clear, logical and coherent. The organization follows a multi-syllabus approach including varied topics, situations, functions, and structures, the goal of which is facilitating communicative competence and enabling students to reach the aforementioned objectives of CEF (can do objectives).

\section{Is an adequate vocabulary list or glossary included?}

$\mathrm{Gu}$ (2003) stresses the use of vocabulary lists as one of the most effective strategies in vocabulary instruction. Contrary to this fact, the textbook lacks any vocabulary list or indices throughout or even at the end.

\section{Are adequate review sections and exercises included?}

Materials should take into account that the positive effects of instruction are usually delayed, meaning that instructions should be recycled. Total English Intermediate includes 10 units. Each unit in turn is comprised of different sections. However, at the end of each unit a single page is dedicated to "Review and practices." This section includes review exercises dealing with the grammar points and vocabulary items of the unit. The exercises are usually of the fillin-the-blank type.

\section{Is an adequate set of evaluation quizzes or testing suggestions included?}


Brown (2004) categorizes tests under the term assessment which in turn is a component of teaching. This idea emphasizes the role of quizzes and test in language teaching. In addition, textbooks are great participants in language teaching and learning. Thus, the incorporation of varied tests and quizzes facilitates the learners' long path in learning a second or foreign language. By including review section at the end of each unit, Total English Intermediate has given due attention to this importance.

12. Does the teacher's book contain guidance about how the textbook can be used to the utmost advantage?

McDonough and Shaw (1993) argue that while some teacher's books give general hints to the teachers, they should also provide non-native teachers with sufficient and clear prescriptions on how to use and teach the textbook. Total English package is supplemented with an edition for teachers which is also published by Pearson Longman in great circulation that is easily accessible on the market. However, the teacher's edition is not that much prescriptive regarding the methodology and only gives general instructions on how to use the textbook.

13. Are the material's objectives apparent to both the teacher and student?

As mentioned earlier, Total English Intermediate is designed based on the standards devised by Common European Framework for teaching European languages. CEF has stated these objectives as "can do" statements that seem to be the functions of language that students should master through reading the textbook.

14. Does the textbook provide a balance of activities (Ex. There is an even distribution of free vs. controlled exercises and tasks that focus on both fluent and accurate production)?

In language teaching, it is important to move from controlled to free practice. Furthermore, both fluency and accuracy should be taken into consideration. Total English Intermediate tries to strike a balance between different types of activities including free and controlled activities, fluency and accuracy activities, and focus on form and focus on forms activities.

15. Do the activities encourage sufficient communicative and meaningful practice?

Brown (2007) believes that meaningful learning will result in better long-term retention. Total English by an integration of all the four language skills as well as inclusion of both control and free practice, has provided students with meaningful practice.

16. Do the activities incorporate individual, pair and group work?

In one hand, Brown (2007) referred to pair and group work as the most appropriate techniques to be implemented in language's courses. On the other hand, it should be born in mind that some learners prefer individual work. Therefore, the activities should include individual, pair and group work in the textbook. Total English has used different techniques to integrate the four language skills. However, most of the group and pair work activities are used to engage the learners to discuss the topics with each other. Individual work has received the greatest prominence. The first activities in each section (grammar, listening, reading, writing, etc.) are mostly of individual type, and they appear to be for warm up purposes.

17. Are the grammar points and vocabulary items introduced in motivating and realistic contexts?

The grammatical structures are presented within inductive approaches. According to research studies in SLA, children benefit more than adults from the inductive approach. However, structures are not presented in a vacuum and are relevant to the "can do" functions and also themes of the unit. The textbook also presents the vocabulary items using different vocabulary learning strategies and activities. Vocabulary presentation is usually integrated with speaking activities.

18. Do the activities promote creative, original and independent responses?

Problem solving activities are at the heart of any ELT textbook which leads in the development of critical thinking in learners' minds. The researchers' general belief is that Total English intermediate uses the elements of the problem solving activities including defining the problem, gathering information, studying and analyzing the collected information, suggesting solutions, evaluating the suggested solutions, solving the problem throughout the activities.

19. Can the textbook's activities be modified or supplemented easily?

McDonough and Shaw (1993) argues that materials modification include adding, deleting, modifying, simplifying and reordering. Total English Intermediate activities are designed in such a way that can be easily modified. All grammar exercises can be added, deleted or even re-ordered.

20. Do the materials provide an appropriate balance of the four language skills?

There seems to be well balanced of incorporation of the four language skills. However, reading skill seems to receive more attention in Total English intermediate. Reading passages are reinforced and recycled throughout the coursebook.

21. Does the textbook highlight and practice natural pronunciation (i.e. stress and intonation)?

Empirical research and pronunciation materials' writers point out the importance of teaching supra-segmental (stress and intonation) before segmental to intermediate and advanced non-native students (NNSs) (Bott, 2005 cited in Pourhosein Gilakjani, 2012). More importantly, Krashen (1985) emphasizes the natural acquisition of pronunciation. Total English Intermediate through authentic listening and proper exercises enables students to implicitly acquire pronunciation points as natural as possible.

22. Is the practice of individual skills integrated into the practice of other skills? 
Brown (2007, p.233) maintains that the integration of the four language skills "gives students greater motivation that coverts to better retention of the principle of effective speaking, listening, reading and writing." The book has paid sufficient attention to the integration of the four language skills specially speaking skill through its content.

23. Does the textbook pay attention to sub skills (i.e. listening for gist, note taking, skimming for information, etc.)?

A great amount literature can be found dealing with making learners conscious of the learning strategies (grammar, vocabulary and reading strategies) through the textbooks (Richards and Schmidt, 2002). Listening for gist, note taking and other listening strategies are rather well incorporated into the textbook. Listening activities mainly include fill-in the-blank, matching, true-false and comprehension activities. Regarding reading comprehension, Tomlinson (2003) argues that there are four main approaches dealing with teaching L2 reading including reading comprehension based, language based, skill/strategy based approach and the schema based approach. Considering Total English Intermediate the researchers observed that the main approach presented in the textbook seems to be the comprehension approach. Thus, the other approaches, specifically skills/ strategy based approach toward reading are seemingly neglected.

24. Is the language used at the right level for the students' current English ability?

Krashen (1981) argue that comprehensible input is the crucial and necessary ingredient for second-language acquisition. Thus, it is essential to provide the student/learner with comprehensible input $[i+1]$ which is slightly more advanced than their current level. To the best of the researchers' knowledge, and after a detailed investigation of the book, Total English intermediate seems to be at the right level for the students' current level.

25. Is the progression of grammar points and vocabulary items appropriate?

In this textbook, grammar points and vocabulary items (Specially vocabulary items) are vastly emphasized. Vocabulary items are incorporated into the four language skills. Review section after each unit seems quite helpful to foster the internalization of grammar points and vocabulary items.

26. Are the grammar points presented with brief and easy examples and explanations?

Although implicit grammar teaching holds a great value in second and foreign language learning, and instruction, explicit grammar teaching should not be missed out specifically teaching adult learner (see Brown, 2007). However, Total English intermediate lacks explicit grammar teaching and only emphasizes implicit grammar teaching.

27. Does the language represent a diverse range of registers and accents?

James (2010 cited in Pourhosein Gilakjani, 2012) maintains that one does not have to try to make his students sound like the Queen of England or the President of the United States. That is, in teaching a foreign language the learners' accents should be close to the standard variety. By the same token, textbook should familiarize students with a diverse range of registers and accents that will in turn allow the student to efficiently understand these varieties. Total English Intermediate seems to have paid enough attention to this fact.

28. Is the subject and content of the textbook relevant to the students' needs as an English language learner(s)?

Using universal themes (friends, media, wealth, etc.) the book has tried to choose the most common elements relevant to the students' needs.

\section{Is the subject and content of the textbook realistic and authentic?}

With the advent of Communicative Language Teaching in 1970s and 1980s, there has been a great concern for the textbook material to be authentic and realistic. The incorporation of authentic listening, speaking, reading and writing enables the students not only to use the language genuinely in real-life situation, but it also enhances the students' motivation (Cathcart, 1989, Lee, 1995). With respect to this issue, materials in the Total English are not manipulated and simplified for the learners. Listening and reading materials are adopted from authenticly from different sources. Furthermore, the textbook is accompanied by a DVD providing the learners with authentic material from movies and TV.

\section{Is the subject and content of the textbook interesting, challenging and motivating?}

The researchers think that the activities contained in Total English Intermediate are both motivating and interesting, and that they generally provide the students with meaningful communication in realistic contexts.

31. Is there sufficient variety in the subject and content of the textbook?

Drawing upon the well-known expression "Variety is the spice of life" one can understand the importance of variety of topics and situations to keep the students motivated and interested. In this respect, Total English Intermediate covers a wide range of topics to keep its content interesting.

32. Are the materials culturally biased and portray any negative stereotypes?

Brown (2007) emphasizes cross-cultural understanding as an important facet of learning a language. He goes on that whenever you teach a language you also teach complex system of cultural systems. Cunningsworth (1984, p.61) holds "A limitation of the culture-specific coursebook is that it will be only of the relevance to students who understand the cultural background in which it is set". Hence, it should be born in mind that no culture is better than other, meaning that cross-cultural differences should be brought into the light, and no single culture or minor group should be singled out. However, Total English Intermediate seems to only stress the American and western cultures. Illustrations throughout the textbook are related to western cultures. Eastern specifically Islamic culture is not well portrayed.

33. Is the textbook appropriate for the language-learning aims of my institution? 
"Communicative language teaching sets as its goal the teaching of communicative competence" (Richards, 2005, p.2). Total English Intermediate which is founded on the base of Common European Framework sees Communicative Language Teaching as its main approach to language teaching. This objective is achieved through using different tasks and activities. The aim of private sectors in Iran is also to improve students' communicative competence and the ability to communicate in real-life situations. Thus, the objectives of the textbook and those of the institution well mesh with each other.

\section{Does the textbook raises students' interest in further English language study?}

Total English Enjoys a variety of activities, topics and functions which make it interesting to the students. Further, by a selection of varied and lively activities, it encourages the students to further their studies beyond the classroom.

\section{Would the evaluators choose to teach this textbook again?}

Based on the evidences provided above, the textbook appears to possess most of the essential criteria which an ELT textbook must contain. The students' needs are likely to be met by this textbook and real-life, authentic language is practiced through the textbook. Thus, the researchers recommend the textbook to be used in the future ELT courses.

In the next section, the teachers' answers to the items of the questionnaire are tabulated. Using descriptive statistics the data obtained from the questionnaire was analyzed. As table 1 indicates, the results approve the researchers' subjective evaluation.

TABLE1.

DESCRIPTIVE STATISTICS OF THE TEACHERS' ANSWERS TO THE ITEMS OF THE QUESTIONNAIRE

\begin{tabular}{|c|c|c|c|}
\hline $\begin{array}{l}\text { Number of } \\
\text { the Question }\end{array}$ & Item & Frequency & $\begin{array}{l}\text { Number of } \\
\text { Patricians }\end{array}$ \\
\hline 1 & The price of the textbook is reasonable. & $28 \%$ strongly agree & 20 \\
\hline 2 & The textbook is easily accessible & $57 \%$ strongly agree & 20 \\
\hline 3 & The textbook is a recent publication. & $71 \%$ strongly agree & 20 \\
\hline 4 & A teacher's guide, workbook, and audio-tapes accompany the textbook. & $57 \%$ agree & 20 \\
\hline 5 & $\begin{array}{l}\text { The author's views on language and methodology are comparable to mine } \\
\text { (Note: Refer to the 'blurb' on the back of the textbook). }\end{array}$ & $\begin{array}{l}42 \% \text { neither agree nor } \\
\text { disagree } 14 \% \text { strongly agree }\end{array}$ & 20 \\
\hline 6 & $\begin{array}{l}\text { The textbook includes a detailed overview of the functions, structures and } \\
\text { vocabulary that will be taught in each unit. }\end{array}$ & $85 \%$ agree & 20 \\
\hline 7 & The layout and design are appropriate and clear. & $57 \%$ agree & 20 \\
\hline 8 & The textbook is organized effectively. & $57 \%$ strongly agree & 20 \\
\hline 9 & An adequate vocabulary list or glossary is included. & $42 \%$ agree & 20 \\
\hline 10 & Adequate review sections and exercises are included. & $57 \%$ agree & 20 \\
\hline 11 & An adequate set of evaluation quizzes or testing suggestions is included & $\begin{array}{l}42 \% \text { neither agree nor } \\
\text { disagree, } 28 \% \text { agree }\end{array}$ & 20 \\
\hline 12 & $\begin{array}{l}\text { The teacher's book contains guidance about how the textbook can be used to the } \\
\text { utmost advantage. }\end{array}$ & $\begin{array}{l}57 \% \text { neither agree, nor } \\
\text { disagree, } 28 \% \text { agree }\end{array}$ & 20 \\
\hline 13 & The materials objectives are apparent to both the teacher and student. & $71 \%$ agree & 20 \\
\hline 14 & $\begin{array}{l}\text { The textbook provides a balance of activities (Ex. There is an even distribution } \\
\text { of free vs. controlled exercises and tasks that focus on both fluent and accurate } \\
\text { production). }\end{array}$ & $42 \%$ agree & 20 \\
\hline 15 & The activities encourage sufficient communicative and meaningful practice. & $28 \%$ strongly agree & 20 \\
\hline 16 & The activities incorporate individual, pair and group work. & $57 \%$ agree & 20 \\
\hline 17 & $\begin{array}{l}\text { The grammar points and vocabulary items are introduced in motivating and } \\
\text { realistic contexts. }\end{array}$ & $42 \%$ agree & 20 \\
\hline 18 & The activities promote creative, original and independent responses. & $28 \%$ strongly agree & 20 \\
\hline 19 & The textbook's activities can be modified or supplemented easily. & $42 \%$ agree & 20 \\
\hline 20 & The materials provide an appropriate balance of the four language skills. & $42 \%$ agree & 20 \\
\hline 21 & $\begin{array}{l}\text { The textbook highlights and practices natural pronunciation (i.e. stress and } \\
\text { intonation) }\end{array}$ & $42 \%$ agree & 20 \\
\hline 22 & The practice of individual skills is integrated into the practice of other skills. & $85 \%$ agree & 20 \\
\hline 23 & $\begin{array}{l}\text { Does the textbook pay attention to sub skills (i.e. listening for gist, note taking, } \\
\text { skimming for information, etc)? }\end{array}$ & & 20 \\
\hline 24 & The language used is at the right level for my (students') current English ability. & $57 \%$ agree & 20 \\
\hline 25 & The progression of grammar points and vocabulary items is appropriate. & $42 \%$ agree & 20 \\
\hline 26 & $\begin{array}{l}\text { The grammar points are presented with brief and easy examples and } \\
\text { explanations. }\end{array}$ & $57 \%$ agree & 20 \\
\hline 27 & The language represents a diverse range of registers and accents. & $42 \%$ agree & 20 \\
\hline 28 & $\begin{array}{l}\text { The subject and content of the textbook is relevant to my (students') needs as an } \\
\text { English language learner(s). }\end{array}$ & $85 \%$ agree & 20 \\
\hline 29 & The subject and content of the textbook is generally realistic and authentic. & $71 \%$ agree & 20 \\
\hline 30 & $\begin{array}{l}\text { The subject and content of the textbook is interesting, challenging and } \\
\text { motivating. }\end{array}$ & $\begin{array}{l}42 \% \text { neither agree nor } \\
\text { disagree, } 28 \% \text { agree }\end{array}$ & 20 \\
\hline 31 & There is sufficient variety in the subject and content of the textbook. & $71 \%$ agree & 20 \\
\hline 32 & $\begin{array}{l}\text { The materials are not culturally biased and they do not portray any negative } \\
\text { stereotypes. }\end{array}$ & $42 \%$ agree & 20 \\
\hline 33 & The textbook is appropriate for the language-learning aims of my institution. & $57 \%$ agree & 20 \\
\hline 34 & The textbook raises my (students') interest in further English language study. & $42 \%$ agree & 20 \\
\hline 35 & I would choose to study/teach this textbook again & $42 \%$ agree & 20 \\
\hline
\end{tabular}




\section{CONCLUSION}

The present study set out to evaluate English language textbook "total English" for intermediate level students. Total English for Intermediate level by Clare and Wilson (2006) (Longman publication), is a course for young adults ad adults which is based on Common European Framework (CEF). It was then scrutinized against forty criterial features based on recent and validated checklist adopted from Litz (2005). The findings of the study indicate that overall, the textbook has met its goals.

\section{APPENDIX A}

1. Is the price of the textbook reasonable?

2. The textbook is easily accessible

3. Is the textbook a recent publication?

4. Is the textbook accompanied by a teacher's guide, workbook, and audio-tapes or CDs?

5. Are the author's views on language and methodology comparable to those held by the evaluators?

6. Does the textbook include a detailed overview of the functions, structures and vocabulary that will be taught in each unit?

7. Is the layout and design appropriate and clear?

8. Is the textbook organized effectively?

9. Is an adequate vocabulary list or glossary included?

10. Are adequate review sections and exercises included?

11. Is an adequate set of evaluation quizzes or testing suggestions included?

12. Does the teacher's book contain guidance about how the textbook can be used to the utmost advantage?

13. Are the materials objectives apparent to both the teacher and student?

14. Does the textbook provide a balance of activities (Ex. There is an even distribution of free vs. controlled exercises and tasks that focus on both fluent and accurate production)?

15. Do the activities encourage sufficient communicative and meaningful practice?

16. Do the activities incorporate individual, pair and group work?

17. Are the grammar points and vocabulary items introduced in motivating and realistic contexts?

18. Do the activities promote creative, original and independent responses?

19. Can the textbook's activities be modified or supplemented easily?

20. Do the materials provide an appropriate balance of the four language skills?

21. Does the textbook highlight and practice natural pronunciation (i.e. stress and intonation)?

22. Is the practice of individual skills integrated into the practice of other skills?

23. Does the textbook pay attention to sub skills (i.e. listening for gist, note taking, skimming for information, etc)?

24. Is the language used at the right level for the students' current English ability?

25. Is the progression of grammar points and vocabulary items appropriate?

26. Are the grammar points presented with brief and easy examples and explanations?

27. Does the language represent a diverse range of registers and accents?

28. Is the subject and content of the textbook relevant to the students' needs as an English language learner(s)?

29. Is the subject and content of the textbook generally realistic and authentic?

30. Is the subject and content of the textbook interesting, challenging and motivating?

31. Is there sufficient variety in the subject and content of the textbook?

32. Are the materials culturally biased and portray any negative stereotypes?

33. Is the textbook appropriate for the language-learning aims of my institution?

34. Does the textbook raises students' interest in further English language study?

35. Would the evaluators choose to teach this textbook again?

\section{REFERENCES}

[1] Brown, H. D. (2004). Language assessment: Principles and classroom practices. White plains, New York: Pearson Education

[2] Brown, H. D. (2007). Teaching by principles: An interactive approach to language pedagogy. White plains, New York: Pearson Education.

[3] Cathcart, R. L. (1989). Authentic discourse and the survival English curriculum. TESOL Quarterly, 23(1), 105-126.

[4] Clare, A., \& Wilson, J. J. (2006). Total English intermediate workbook. United Kingdom: Pearson Education

[5] Cunningsworth, A. (1984). Evaluating and selecting EFL teaching materials. London: Heinemann.

[6] Cunningsworth, A. (1995).Choosing Your Coursebook. London: Heinemann.

[7] Ellis, R., Johnson, K. E., Henry, A., \& Roseberry, R. L. (1998). An Evaluation of a Genre Based Approach to the Teaching of EAP/ESP Writing. Tesol Quarterly, 32(1), 147-156.

[8] Gilakjani, A. P. (2012). The Significance of Pronunciation in English Language Teaching. English Language Teaching, 5(4), 96-107.

[9] Krashen, S. (1981). Second language acquisition and second language learning. Oxfore: Pergamon Press

[10] Krashen, S. D. (1985). Language acquisition and language education. Prentice Hall, Englewood Cliffs. 
[11] Hutchinson, T., \& Torres, E. (1994). The textbook as agent of change. ELT journal, 48(4), 315-328.

[12] Lee, W. Y. C. (1995). Authenticity revisited: Text authenticity and learner authenticity. ELT journal, 49(4), 323-328.

[13] Litz, D. R. (2005). Textbook evaluation and ELT management: A South Korean case study. Asian EFL journal, 6(4). 2-52.

[14] McDonough, J. A., \& Shaw, C. (1993). Materials and methods in ELT: A teacher's guide. Oxford, England: Blackwell.

[15] McGrath, I. (2002). Materials evaluation and design for language teaching. Edinburgh, Scotland: Edinburgh University Press

[16] Merriam-Webster, Inc (Ed.). (2003). Merriam-Webster's collegiate dictionary. Merriam-Webster.

[17] Richards, J. C. (2005). Communicative language teaching today. SEAMEO Regional Language Centre.

[18] Rubdy, R. (2003). Selection of materials. In B. Tomlinson (Ed.), Developing materials for language teaching (pp. 37-57). London, UK: Continuum.

[19] Sheldon, L. E. (1988). Evaluating ELT textbooks and materials. ELT journal, 42(4), 237-246.

[20] Tomlinson, B. (2003). Developing materials for language teaching. London: Bloomsbury Academic

[21] Tomlinson, B. (2005). Developing materials for language teaching. Continuum.

[22] Tomlinson, B. (Ed.). (2011). Materials development in language teaching. Cambridge:_Cambridge University Press.

[23] Williams, D. (1983). Developing criteria for textbook evaluation. ELT journal, 37(3), 251-255.

Ismail Moazam, a postgraduate in TEFL from department of English language and literature faculty of literature and humanities Bu-Ali Sina University (Hamedan- Iran) has published some articles in both national and international academic journals.

Hojat Jodai is a PhD student in TEFL, department of English language and literature faculty of literature and humanities Hakim Sabzevari University (Iran). He has published numerous papers in applied linguistics journals both nationally and internationally. 